\title{
Research on Copyright Protection of Computer Games
}

\author{
Xiang hua Deng ${ }^{1}$ and Dan Liu ${ }^{1, *}$ \\ ${ }^{1}$ Department of Law, Wuhan Dong hu University, Wuhan, Hubei, 430212, China
}

\begin{abstract}
With the development of the Internet economy, computer games have developed rapidly in recent years. At the same time, with the increasing prosperity of computer games, many infringement problems have also arisen. The concept and classification of computer games and computer game live broadcasts, as well as computer game screens and computer game live broadcasts need to be distinguished. The article lists common problems in the computer game live broadcast industry, which are mainly manifested in the unclear copyright identification and attribution of computer game live broadcasts, and the unclear legal status of the relevant subjects in the computer game live broadcast. It is concluded that whether the computer game live broadcast is a work needs to be specifically defined in conjunction with the live broadcast content. And further put forward suggestions to improve my country's related protection system of computer game copyright, and promote the development of computer game live broadcast industry.
\end{abstract}

\section{Introduction}

With the development of computer technology and the emergence of mobile Internet, computer game live broadcasts are becoming more and more attractive to netizens. According to Table 1 China Internet Network Information Center statistics show that as of June 2019, the number of online live broadcast users in my country reached 433 million, an increase from the end of 2018 36.46 million, accounting for $50.7 \%$ of the total netizens.

Table1. 2016.6-2019.6 webcast user scale

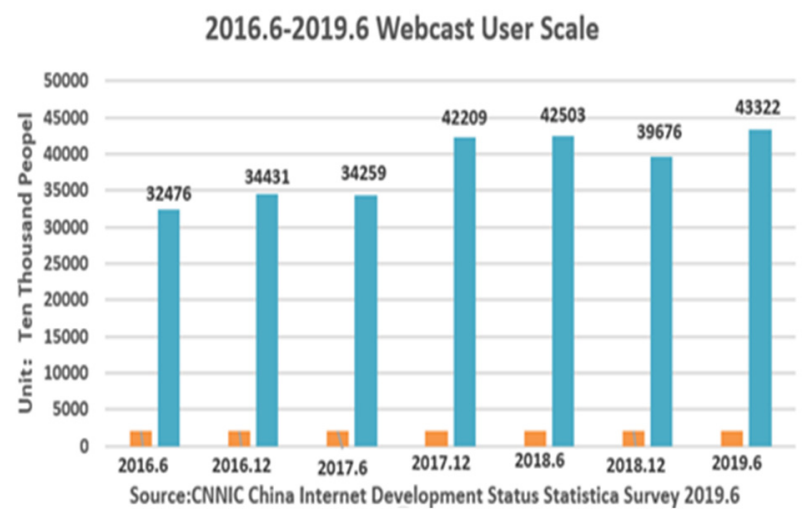

Among the computer network live broadcast users in my country in 2019 , the user scales of reality show live broadcast and sports live broadcast were 205 million and 194 million, accounting for $24.0 \%$ and $22.7 \%$ of the total netizens respectively; the user scale of game live broadcast and concert live broadcast were 243 million respectively, 116 million, accounting for $28.4 \%$ and $13.6 \%$ of the total netizens respectively. It can be seen that the computer game live broadcast has accounted for a very large proportion of all users. But while the industry is developing rapidly, the existing problems are also expanding. At present, there are many controversies in my country regarding the infringement issues arising from the live broadcast of computer games. Research on copyright protection in computer game live broadcasts, and continuous protection of copyrights from many aspects, will help to further improve the protection of such copyrights.

\section{The status quo of copyright protection in computer games in my country}

\subsection{Legislation status}

The 2016 Internet Service Management Regulations require that live broadcasts should not be used to spread obscene videos, and that live broadcasts should not be used to disrupt social stability or spread rumors. Do not spread matters that are not allowed by the law to endanger national security. In 2018, the "Guidelines for the Trial of Copyright Infringement Cases" recognized the copyright of computer software and stipulated in Article 14 and Article 15 that static images of computer games could constitute works of art and be protected by law. The uninterrupted dynamic picture produced by it can conform to the movie-like form and is also protected by copyright. Some individual elements in computer games, such as costumes, opening animations, game episodes, game props, maps, etc., that can constitute works are also protected by copyright law. my country's current copyright law does not specify the copyright of game screens and the copyright of live game screens, but only stipulates that computer games can be regarded as computer software. This shows that the Internet live broadcast industry is developing rapidly, but 
my country's regulations on copyright protection of this kind are lagging behind.

\subsection{Judicial status}

Due to the gaps in the legislation on copyright in live game broadcasting, the judgments of some cases have caused difficulties and contradictions. For example, in the "Fantasy Westward Journey 2" case, the judge did not elaborate on the copyright attributes of the game screen and the live screen, but many scholars have put forward different views on this. In the Yaoyu v. Douyu case, the Douyu platform provided a barrage and commented on the game events, which was original, but constituted unfair competition[1]. Among them, whether such issues can be regarded as fair use has been controversial in the industry. There is a view that the live broadcast of it has not caused some problems for game manufacturers, and can attract more game players, and believe that it can be considered as a fair use. Another part of the view is that fair use infringes on the interests of game manufacturers. For example, selling pirated DVDs and novels can also promote the spread of works, but this does violate the legal principles of copyright.

\subsection{Current status of industry regulations}

Our country does not have an organization that specializes in managing the live broadcast of computer games, only some regulations issued by the state restrict the live broadcast of the web. This is a great test for the personal quality of the anchor and the platform's own supervision. At present, many platforms in the country mostly supervise the behavior of the anchors by setting up platform supermanagement. However, in the absence of strict supervision and self-control by the platform and the anchor, the situation is not optimistic. Logging on to the live broadcast platform can often see many computer game anchors infringing copyright. For the healthy development of the computer game live broadcast industry, a live broadcast platform regulator should be established instead of relying solely on the industry's own consciousness.

\section{Problems of copyright protection in live broadcast of computer games}

Anchors and live broadcast platforms earn benefits through computer game live broadcasts. Whether this part of the property benefits must be licensed by the game copyright owner, and whether the necessary license fees must be paid to the game copyright owner. Which right in the Copyright Law regulates, including Performance rights, broadcasting rights, information network dissemination rights, and allround rights, etc., whether computer game live broadcast constitutes a restriction under the Copyright Law, and whether unauthorized computer game live broadcast constitutes infringement, etc. These questions are very controversial both in theory and in practice, and there is no unified standard answer so far.

\section{Regulations on the protection of the copyright of the live broadcast of computer games abroad}

\section{1 ited States}

The video game industry was first created in the United States, and the United States has long been involved in the regulation of the copyright of computer game live broadcasts. We can learn from how the United States protects the copyright of live computer games. In the Sent Electric v. Kaufman case in the United States in 1982, the court held that although games are independently run by computer programs, they can be independently protected by copyright as computer software. However, the game screen presented by running the game can still be used as audiovisual works for legal protection. The United States is a case law country, and we can provide good materials for my country's legislation based on the United States' handling of such cases. In the US game industry, the US has adopted copyright laws to eliminate industry norms, severely crack down on piracy, support original creation, and conduct supervision and management through specialized organizations[2].

\subsection{Japan}

Japan is a very developed country in the video game industry in the world, and there have been early researches on this type of copyright protection in Japan. Japan's legal protection of online game screens is not much different from that of the United States. Japan treats the screens as movie-like works for copyright protection. At present, the regulations on computer game screens in my country's "Guide" are the same as those in Japan. When the game screen is a continuous dynamic screen, it can constitute a movie work for copyright protection; when the game screen is a static screen, it meets the conditions of an art work This can be protected by copyright.

\subsection{Korea}

The copyright of computer games in South Korea is mainly protected by the "Computer Program Protection Act" and "Korea Copyright Act." In the copyright law, South Korea treats game screens as movie-like works for protection, and when they are not enough to be recognized as movie-like works, they treat them as computer programs for protection. South Korea pays more attention to copyright than my country. For the better and healthy development of the game industry in our country, we must attach importance to copyright issues[3].

\subsection{The Enlightenment of Protecting Copyright Outside the Territory}

From the perspective of these three countries outside the region, foreign academic circles are more inclined to treat computer game live images as audiovisual works for legal protection. Through the self-discipline of industry 
associations and standardized laws to eliminate the entire industry, the entire game industry and the game live broadcast industry can develop healthily.

\section{Suggestions on Copyright Protection in Live Broadcast of Computer Games}

\author{
5.1 Defining and protecting the attributes of \\ works
}

In China, the game screen and the live broadcast screen are now defined, but the boundary for determining the attributes of their works is blurred. The 2018 "Guide" has clearly pointed out that the static images of computer games can constitute works, which can be used as art works for copyright protection; the continuous uninterrupted dynamic images produced by running computer games can be regarded as film works. Copyright protection. There is no domestic law regarding the live broadcast that recognizes it as a work. The comparative study and the enlightenment given to us by the protection of copyright outside the territory, the live broadcast should belong to the performer's rights of the host, and the live broadcast of online games can be protected through the protection of neighboring rights.

\subsection{Improve the copyright system}

At present, my country's copyright law does not explicitly include computer game screens in the category of works, nor does it provide for live broadcast screens. However, the "Guide" has clearly stated that when a computer game screen meets certain conditions, it can be used as a work of art and a movie-like work. Drawing lessons from some foreign practices and Taiwan's protection methods, computer game screens can be treated as audiovisual works and computer programs for copyright protection. The live broadcast picture can be clearly determined in the copyright law as a product of performance rights, which is a kind of neighboring rights. In summary, by dividing it into fine art works, audiovisual works, and computer programs, it is included in the types of works specified in the Copyright Law for copyright protection. The copyright law improves the relevant regulations on the live game screen, supplements the blank area of my country's existing copyright law, and provides effective legal protection for the industry.

\subsection{Establish a system of liability for infringement of online game live broadcast copyright}

On the computer game live broadcast platform, the game host broadcasts the game without the permission of the copyright owner. How to divide the infringement liability of game anchors and game live broadcast platforms. Generally, there are two types of game anchors. One is that the game anchor directly signs a contract with the platform to sign a labor contract. The other is that the anchor broadcasts live on the platform and does not sign a labor contract, but earns income by receiving gifts. In the former method, the game anchor belongs to the employee of the live broadcast platform, and the live broadcast platform shall bear the main responsibility when the anchor conducts infringement live broadcast. In the latter method, the game anchor conducts piracy, and the live broadcast platform should be obliged to warn or close its live broadcast room. If the live broadcast platform fails to fulfill the relevant obligations, the live broadcast platform should also bear certain responsibilities.

\subsection{Strengthen the supervision of the online game live broadcast industry}

The live broadcast industry is growing rapidly, and effective supervision agencies are indispensable for its healthy and smooth development. At present, the supervision of the live broadcast industry in my country is chaotic, and there is no special agency for supervision. Many organizations conduct inspections on the industry, resulting in uneven distribution of supervisory responsibilities. The industry has not yet constructed a unified industry organization for self-management. The establishment of a special supervision and guarantee agency is an effective method. The game live broadcast industry needs to improve industry self-discipline, and the requirements for anchors should also be stricter. Establishing a unified industry association for management and strengthening the supervision of the computer game live broadcast industry will be more conducive to the vigorous development of the industry.

\section{Conclusion}

With the rapid development of the Internet age, the computer game live broadcast industry has become a sunrise industry in our country, but just as every new thing is accompanied by problems and chaos, copyright disputes in computer game live broadcasts frequently appear, causing a wide range of Concerns and disputes, although many experts and scholars have been arguing, they still have not given an accurate standard and answer. This makes the copyright issue of computer game live broadcast a hot and difficult point in the legal world.

The speed of scientific and technological upgrading is beyond our imagination. In addition to the live broadcast of computer games, there will be more new models and new types of new works in the future. This is the torrent of the development of the times and the trend of the industry. No one can It is foolish and wrong to block and become an enemy. It is the only way for a really smart person to put a right attitude and strive to face up to the trend of the times. The computer game live broadcast industry, which has experienced rapid iterative development, has now entered the "golden age" and will become one of the most beneficial industries driven by $5 \mathrm{G}$ development. Therefore, it is necessary to improve the legal system and strengthen supervision to better ensure that the computer game live broadcast industry enters the fast lane in a healthy and stable manner. 


\section{Acknowledgement}

This article is part of the research results of the 13th FiveYear Plan of the Education Branch of the China Information Association, The Reform and Response of Law Higher Education in the Era of Artificial Intelligence (project number: ZXXJ2020017).

\section{References}

1. Wang Xiao, A Preliminary Study on the Copyright Protection Scope of Video Games_-From the Perspective of Game Designers, Electronics Intellectual Property, pp. 75-82, Issue6, 2016

2. Greg Lastowka, Copyright Law and Video Games: A Brief History of an Interactive Medium, pp.11-12, 2013

3. Jacob Rogers, Crafting an Industry:An Analysis of Korean Star Craft and Intellectual Properties Law, Harvard Journal of Law and Technology Digest, pp. 50-51, Issue11, 2012

4. Wang Qian, The legal nature of the network anchors performing songs in direct broadcasting, Chinese Version Quan, pp. 24-29, Issue 5, 2018 